\title{
Oxygen-Plasma Surface Treatment of an Electrode Sheet Using Carbon from Japanese Distilled Liquor Waste for Double-layer Capacitors
}

\author{
Daisuke Tashima $^{1, * \mathbb{C}}$, Masaki Hirano ${ }^{1}$, Satoshi Kitazaki ${ }^{1} \mathbb{D}$, Takuya Eguchi ${ }^{2}$ and \\ Seiji Kumagai ${ }^{2}$ (D) \\ 1 Department of Electrical Engineering, Fukuoka Institute of Technology, Fukuoka 811-0295, Japan; \\ mem18108@bene.fit.ac.jp (M.H.); kitazaki@fit.ac.jp (S.K.) \\ 2 Department of Mathematical Science and Electrical-Electronic-Computer Engineering, Akita University, \\ Akita 010-8502, Japan; d8519003@s.akita-u.ac.jp (T.E.); kumagai@gipc.akita-u.ac.jp (S.K.) \\ * Correspondence: tashima@fit.ac.jp; Tel.: +81-92-606-4704
}

Received: 28 July 2020; Accepted: 26 August 2020; Published: 1 September 2020 updates

\begin{abstract}
Oxygen-plasma treatment was performed on an activated carbon sheet obtained from shochu (Japanese distilled liquor) waste using a high-frequency plasma generator. The capacitances of the activated carbon sheet electrode subjected to surface treatment were measured using cyclic voltammetry. The best results were obtained with a processing time of $60 \mathrm{~min}$, an output power of $40 \mathrm{~W}$, an interelectrode distance of $13 \mathrm{~cm}$ and an oxygen pressure of $40 \mathrm{~Pa}$. The maximum capacitance was $247 \mathrm{~F} \mathrm{~g}^{-1}$. Investigation of the surface functional groups of the activated carbon sheet revealed that the oxygen-containing functional groups modified on the surface of the activated carbon sheet electrode contributed to the improvement in the capacitance. High-performance electric double-layer capacitors can be realized using the developed electrodes.
\end{abstract}

Keywords: plasma treatment; surface modification; Japanese distilled liquor waste; electric double-layer capacitors

\section{Introduction}

Global $\mathrm{CO}_{2}$ emissions are increasing at an astonishing rate as global energy consumption increases, owing to the rapid expansion of the global economy and population. Therefore, clean and sustainable energy conversion and saving systems are needed to mitigate the effects of these emissions. Recently, electric double-layer capacitors (EDLCs) [1] exhibiting long life, high-power density, and fast charge/discharge capabilities have attracted considerable attention. However, compared with chemical batteries, they have disadvantages of low-energy density and high cost.

Shochu [2-4] is a type of Japanese distilled liquor; its production is flourishing in Japan. However, shochu waste generated during manufacturing is a problem, as approximately twice the amount of the product is discarded during the production of shochu. Prior to 2001, this waste was primarily dumped into the ocean; however, this activity has been banned since 2001 for environmental protection according to the Treaty of London $[5,6]$. In this work, we aim to upgrade the low-to-no value shochu waste into high-value carbon materials for energy application.

The most important factor regarding EDLCs is the improvement of the energy density. To improve the energy density of EDLCs, the use of mixed electrodes of graphene [7] and vanadium oxide [8], mixed electrodes with three-dimensionally arranged cobalt and carbon nanofibers [9] with hybrid-type electrodes of different positive and negative electrodes, and pseudocapacitive electrode [10] have been proposed. An improvement in the energy density requires an improvement in the capacitance. 
The primary raw material used in EDLCs is activated carbon, and the capacitance of an EDLC is largely related to the performance of the activated carbon. Regarding the surface treatment of carbon materials with oxygen plasma, Lin et al. [11] used carbon nanotubes and Sahoo et al. [12] used vertical graphene nanosheets and investigated the effect of increasing the oxygen-containing functional groups on the capacitance. In particular, it was revealed that the carbonyl functional group contributes to the increase in the specific capacitance. However, this study differs from other existing studies in that a sheet electrode made of activated carbon having a high specific surface area was subjected to plasma treatment using only oxygen. Therefore, in this study, we investigated the change in the surface state of an activated carbon sheet electrode and its influence on capacitance when shochu waste was used as the EDLC electrode. Furthermore, the original contribution of this study is that we found that a stable capacitance could be achieved even in a long-term test of 10,000 cycles.

\section{Experiments}

\subsection{Preparation of Activated Carbon}

In our experiment, wheat shochu waste was used as the raw material. The waste was placed in a container and carbonized in the presence of nitrogen gas flow $\left(700 \mathrm{~mL} \mathrm{~min}^{-1}\right)$ at $600{ }^{\circ} \mathrm{C}$ at an increasing temperature rate of $5^{\circ} \mathrm{C} \mathrm{min}^{-1}$ for $1 \mathrm{~h}$ in an electric furnace (TMF-700 N, AS ONE, Osaka, Japan). Carbide and 8-M potassium hydroxide $(\mathrm{KOH})$ solution (169-20365, FUJIFILM Wako Pure Chemical Corporation, Osaka, Japan) were mixed at a weight ratio of $1: 1$. The mixture was maintained at $25^{\circ} \mathrm{C}$ for $24 \mathrm{~h}$ to impregnate the carbide with $\mathrm{KOH}$. The impregnated carbide was activated at $800^{\circ} \mathrm{C}$ for $1 \mathrm{~h}$ in an electric furnace at a heating rate of $5{ }^{\circ} \mathrm{C} \mathrm{min}^{-1}$ under nitrogen gas flow. To remove the excess $\mathrm{K}^{+}$ from the activated carbon, the activated carbon was reacted with 1-M hydrochloric acid (086-03925, Wako Pure Chemical Industries, Osaka, Japan) and rinsed with pure water to achieve a $\mathrm{pH}$ value close to 7.0. The washed activated carbon was dried at $100^{\circ} \mathrm{C}$.

\subsection{Preparation of Activated Carbon Sheet Electrode}

A sheet electrode was fabricated with the activated carbon and subjected to oxygen-plasma treatment. The activated carbon sheet electrode was composed of activated carbon, a conductive filler (Ketjenblack (KB) EC-600JD, Lion Corporation, Sumida-ku, Tokyo, Japan) and a polytetrafluoroethylene binder (21,539-100, Polysciences, USA) mixed at a weight ratio of 8:1:1. Circular sheet electrodes (diameter $=10 \mathrm{~mm}$, thickness $=550 \mu \mathrm{m}$ and weight $=17.5 \mathrm{mg}$ ) were prepared with a hot press set at a temperature of $130^{\circ} \mathrm{C}$ and a pressure of $5 \mathrm{MPa}$ by placing the mixture on a nickel mesh (NI-318100, Nilaco, Chuo-ku, Tokyo, Japan) as the collector electrode.

\subsection{Oxygen-Plasma Irradiation Experiment}

To increase the capacitance of the activated carbon sheet electrode, we performed surface treatment using oxygen plasma with a high-frequency power supply. The pressure in the vacuum tube was reduced with a vacuum pump (EN-8T1, ANEST IWATA, Yokohama, Kanagawa, Japan), and high-frequency power was supplied at $13.56 \mathrm{MHz}$ from a high-frequency power source (T161-5566AF, THAMWAY, Fuji, Shizuoka, Japan) to an antenna installed in the vacuum tube to generate oxygen plasma. The experiment was conducted by changing four parameters: processing time, output power, distance between electrodes (wire antenna as positive and the sample as negative) and oxygen pressure. Twelve samples were produced. Figure 1 shows the experimental setup for the plasma treatment and Table 1 lists the conditions based on which the measurements were conducted. 


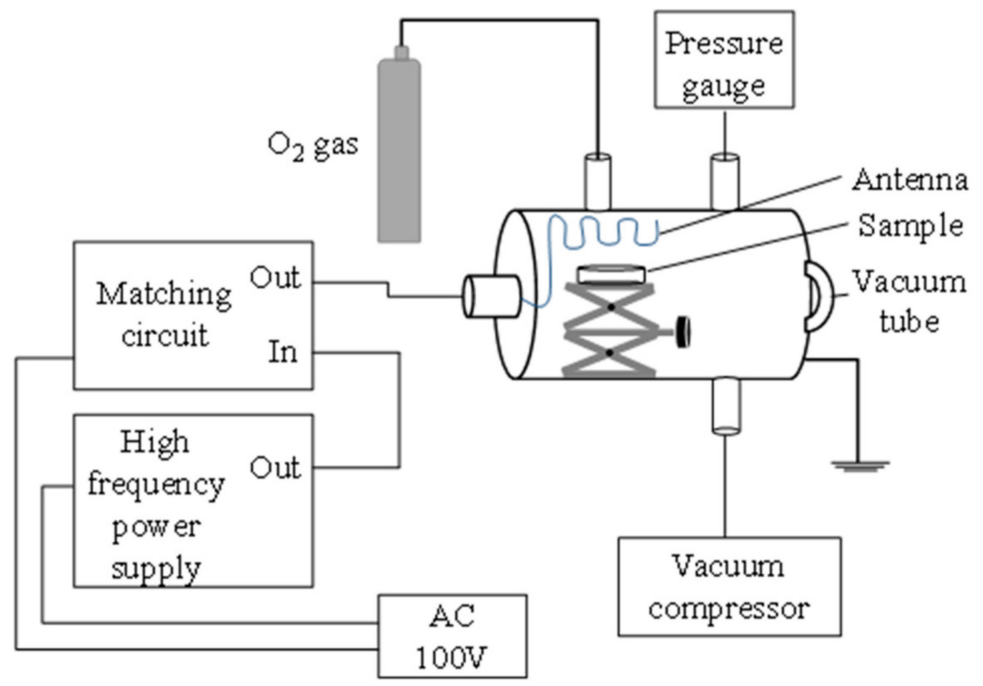

Figure 1. Experimental setup for plasma treatment.

Table 1. Processing parameters for the experimental and specific capacitances.

\begin{tabular}{|c|c|c|c|c|c|}
\hline Sample Name & $\begin{array}{l}\text { Processing Time } \\
\text { (min) }\end{array}$ & $\begin{array}{l}\text { Power Output } \\
\text { (W) }\end{array}$ & $\begin{array}{l}\text { Distance between } \\
\text { Electrodes (cm) }\end{array}$ & $\begin{array}{c}\text { Oxygen Pressure } \\
(\mathrm{Pa})\end{array}$ & $\begin{array}{c}\text { Specific Capacitances } \\
\left(\mathrm{F} \mathrm{g}^{-1}\right)\end{array}$ \\
\hline & \multicolumn{4}{|c|}{ Without plasma treatment } & 234 \\
\hline PT1 & 30 & 40 & 3 & 40 & 219 \\
\hline PT2/PO3/DE1 & 60 & 40 & 3 & 40 & 241 \\
\hline PT3 & 90 & 40 & 3 & 40 & 223 \\
\hline PO1 & 60 & 20 & 3 & 40 & 211 \\
\hline $\mathrm{PO} 2$ & 60 & 30 & 3 & 40 & 240 \\
\hline $\mathrm{PO} 4$ & 60 & 60 & 3 & 40 & 239 \\
\hline PO5 & 60 & 80 & 3 & 40 & 222 \\
\hline DE2 & 60 & 40 & 8 & 40 & 229 \\
\hline DE3/OP2 & 60 & 40 & 13 & 40 & 247 \\
\hline OP1 & 60 & 40 & 13 & 20 & 167 \\
\hline OP3 & 60 & 40 & 13 & 60 & 160 \\
\hline
\end{tabular}

\subsection{Characterization of Activated Carbon Sheet Electrode}

The capacitance of the activated carbon sheet electrode was measured with an electrochemical measuring device (HZ-5000, Hokuto Denko Co., Ltd., Meguro-ku, Tokyo, Japan). A Pt counter electrode and an $\mathrm{Ag} / \mathrm{AgCl}$ reference electrode were used for cyclic voltammetry $(\mathrm{CV})$. The measurements were performed at a sweep rate of $10 \mathrm{mV} \mathrm{s}^{-1}$ within a voltage range of $0-1 \mathrm{~V}$ in a $0.5-\mathrm{M} \mathrm{KOH}$ electrolyte. The capacitance was calculated from the $\mathrm{CV}$ measurements. We assumed that when the potential (V) applied to the working electrode is swept anodically or cathodically from $V_{1}$ to $V_{2}$ at a constant scan rate $\left(r_{s}\right)$, a current, $i$, as a function of time, $t$, flowed to yield a total charge of $-Q$ or $+Q$ in each scan. The total charge is given by half the area $S_{c}$ of the rectangular $i-V$ curve, which is then scaled by the mass of the activated carbon materials, $\mathrm{m}(\mathrm{g})$. Hence, the capacitance $\mathrm{C}\left(\mathrm{F} \cdot \mathrm{g}^{-1}\right)$ of the EDLC can be evaluated by Equation (1) using the total one-way scan time, $\mathrm{t}_{\mathrm{s}}(\mathrm{s})$ :

$$
C\left(F \cdot g^{-1}\right)=\frac{\int_{0}^{t_{s}} i d t}{m \int_{V_{1}}^{V_{2}} d V}=\frac{\frac{1}{r_{s}} \int_{V_{1}}^{V_{2}} i d V}{m \int_{V_{1}}^{V_{2}} d V}=\frac{\frac{1}{2 r_{s}} S_{c}}{m\left(V_{2}-V_{1}\right)}
$$

To confirm the deterioration characteristics, 10,000 test cycles were performed. The other conditions were not changed. The charge transfer and solution resistances were measured using the constant potential alternating current (AC)-impedance method. An AC was applied to the activated carbon sheet electrode in the frequency range of $10 \mathrm{mHz}$ to $20 \mathrm{kHz}$ with an amplitude of $10 \mathrm{mV}$. 
An impedance measurement system (FRA 5022, NF Co., Yokohama, Kanagawa, Japan) was used for the measurements. The surface functional groups on the surface of the activated carbon were analyzed using Fourier-transform infrared spectroscopy (FTIR). Untreated activated carbon and the best-performing activated carbon were used in the measurements. The wavenumber resolution was $4 \mathrm{~cm}^{-1}$, the measurement range was $500-4000 \mathrm{~cm}^{-1}$, and the integration was performed 36 times. An FTIR spectrometer (Cary670, Agilent Technologies, Santa Clara, CA, USA) was used as the measuring device.

\section{Results and Discussion}

The measurement results from $\mathrm{CV}$ and the AC impedance method are shown in Figure 2. The capacitance values are also listed in Table 1 . When the surface treatment was carried out by changing the processing times (PT1-3), the capacitance of the activated carbon sheet electrode with a processing time of $60 \mathrm{~min}$ (PT2) increased by approximately $4 \%$ compared with that of the untreated one. However, at processing times of $30 \mathrm{~min}$ (PT1) and $90 \mathrm{~min}$ (PT3), the capacitances decreased. This could be attributed to the change in the type of surface functional group according to the processing time. When the surface treatment was performed by changing only the output power (PO1-5), the capacitance increased at rated output powers of $30 \mathrm{~W}$ (PO2), $40 \mathrm{~W}$ (PO3) and $60 \mathrm{~W}$ (PO4). At rated output powers of $20 \mathrm{~W}$ (PO1) and $80 \mathrm{~W}$ (PO5), the capacitance decreased. This is possibly because the change in the surface area depends on the power output [13]. When the surface treatment was performed by changing only the distance between the electrodes (ED1-3), the capacitance of the sample with an interelectrode distance of $13 \mathrm{~cm}$ (DE3) increased by approximately 6\% compared with the untreated one. The charge-transfer resistance increased by approximately $41 \%$. This could be attributed to the surface functional groups that contributed to the increase in capacitance $[11,14,15]$. When the surface treatment was performed based only on oxygen pressure changes (OP1-3), the capacitance decreased at $20 \mathrm{~Pa}(\mathrm{OP} 1)$ and $60 \mathrm{~Pa}$ (OP3), resulting in an increase in the charge-transfer resistance. The reason for the change in the capacitance due to the change in gas pressure is considered to be the change in the concentration of oxygen ions ionized by the plasma. When the pressure is low, the oxygen ion concentration is low, and the surface functional groups are not easily formed. Although the oxygen ion concentration also increases as the pressure increases, it is considered that when many surface functional groups are formed, the ions are unable to enter the pores and the capacity decreases. It was observed that the charge transfer resistance increased owing to the formation of the oxygen-containing surface functional group. However, this does not significantly affect ion migration, instead, the solution resistance, which is the real resistance component, decreases and the capacitance increases; therefore, it is considered that the slight increase in the charge transfer resistance is unavoidable. The maximum capacitance of $247 \mathrm{~F} \mathrm{~g}^{-1}$ was obtained for the activated carbon sheet electrode treated with oxygen plasma subject to the following processing conditions (corresponding to sample DE3/OP2): processing time $=60 \mathrm{~min}$, output power $=40 \mathrm{~W}$, electrode distance $=13 \mathrm{~cm}$ and oxygen pressure $=40 \mathrm{~Pa}$. This result could be attributed to the progress of hydrophilization based on the introduction of oxygen-containing functional groups [16-18]. The variation of the capacitance during the execution of 10,000 cycle tests and the corresponding FTIR spectra of plasma-treated and untreated samples are shown in Figure 3. From the maximum capacitance of $247 \mathrm{~F} \mathrm{~g}^{-1}$, the capacitance continues to decrease until the completion of approximately 2000 cycles. It takes some time for the plasma-treated carbon sheet electrode to become compatible with the aqueous electrolytic solution. Therefore, it is considered after the completion of approximately 3000 cycles. Subsequently, it stabilized at approximately $195 \mathrm{~F} \mathrm{~g}^{-1}$. The final capacitance reduction rate was approximately $20 \%$. It was clarified that the plasma-treated sample was able to maintain $80 \%$ of the initial value without decreasing the capacitance even after 3000 cycles. The performances of the untreated activated carbon and the best-performing activated carbon $(60 \mathrm{~min}, 40 \mathrm{~W}, 13 \mathrm{~cm}, 40 \mathrm{~Pa})$, that is sample DE3/OP2, were also compared in the FTIR spectrum. A C-O peak was observed between $1000 \mathrm{~cm}^{-1}$ and $1300 \mathrm{~cm}^{-1}$, a $\mathrm{C}=\mathrm{O}$ peak was detected at $1700 \mathrm{~cm}^{-1}$, and a $-\mathrm{OH}$ peak was detected in the range of $3200-3600 \mathrm{~cm}^{-1}$. 
The functional groups that contained the hydroxyl group $(-\mathrm{OH})$, carboxyl group $(-\mathrm{COOH})$ and carbonyl group $(-\mathrm{C}=\mathrm{O})$ increased.

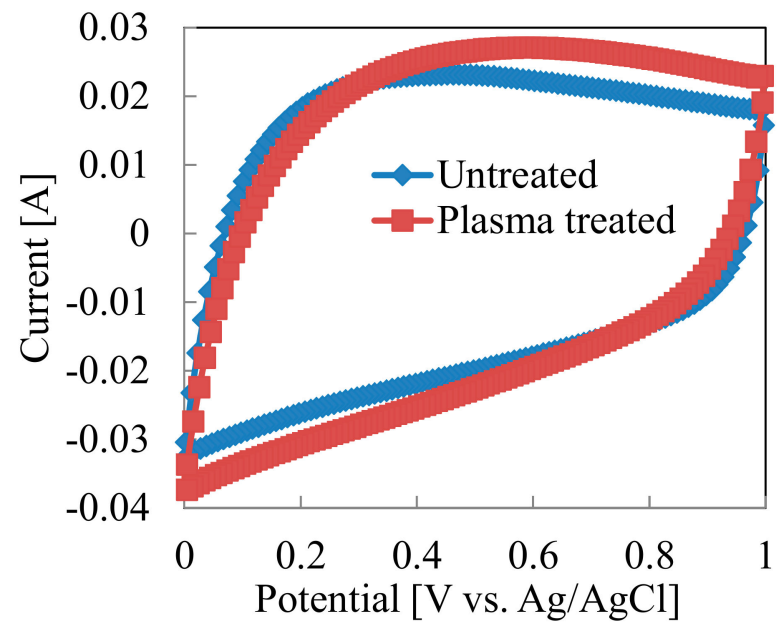

(a)

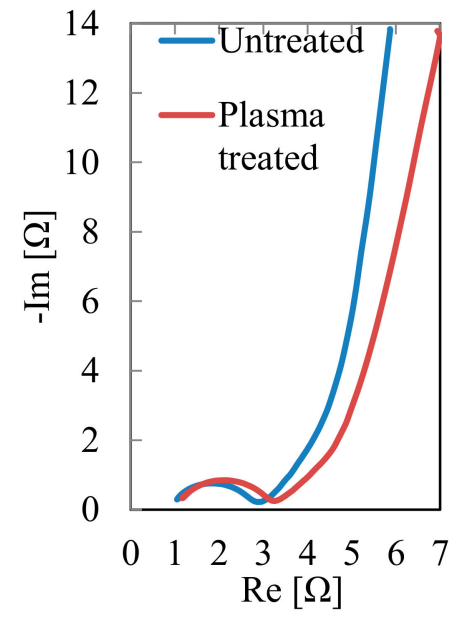

(b)

Figure 2. Results of electrochemical measurement. (a) Cyclic voltammogram and (b) AC impedance of untreated sample and plasma-treated sample (DE3/OP2).
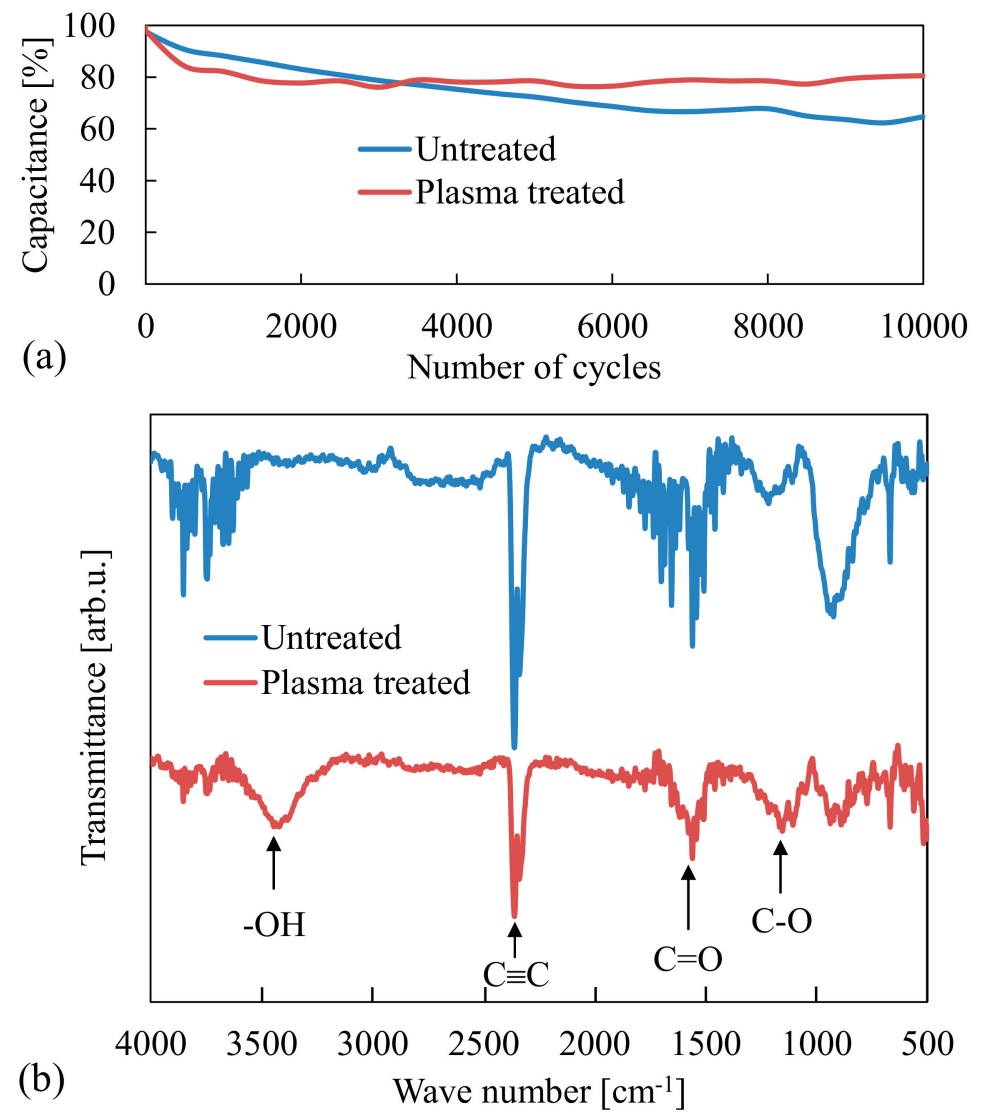

Figure 3. Results of variations of the untreated sample and plasma-treated sample (DE3/OP2). (a) Capacitance during 10,000 cycle tests and (b) FT-IR spectrum 


\section{Conclusions}

In this study, experiments were conducted based on surface changes following oxygen-plasma surface treatments and control of the oxygen-containing functional groups based on improvement in the capacitance of activated-carbon sheet electrodes fabricated from shochu waste for use in EDLCs. Our results yielded a maximum capacitance of $247 \mathrm{~F} \mathrm{~g}^{-1}$. Further, an increase in the oxygen-containing functional group was also confirmed after the surface treatment. The advantage of EDLC is that the capacitance can be improved without impairing its long-cycle lifetime.

Author Contributions: D.T.: conceptualization, funding acquisition, writing-2014 review \& editing. M.H.: data curation. S.K. (Satoshi Kitazaki): methodology. T.E.: investigation. S.K. (Seiji Kumagai): resources. All authors have read and agreed to the published version of the manuscript.

Funding: This work was supported by a Scientific Research Grant from the Japanese Society for the Promotion of Science KAKENHI (Grant number 18K11717).

Conflicts of Interest: The authors declare no conflict of interest.

\section{References}

1. Conway, B.E. Electrochemical Supercapacitors: Scientific Fundamentals and Technological Applications; Plenum Press: New York, NY, USA, 1999; p. 698.

2. Kida, K.; Morimura, S.; Sonoda, Y. Accumulation of propionic acid during anaerobic treatment of distillery wastewater from barley-Shochu making. J. Ferment. Bioeng. 1993, 75, 213-216. [CrossRef]

3. Kida, K.; Sonoda, Y. Influence of mineral nutrients on high performance during anaerobic treatment of distillery wastewater from barley-Shochu making. J. Ferment. Bioeng. 1993, 75, 235-237. [CrossRef]

4. Yokoyama, S.; Tarumi, S. Production and some properties of low-salt seasoning from Shochu distillery waste. J. Biosci. Bioeng. 2001, 92, 200. [CrossRef]

5. Convention on the Prevention of Marine Pollution by Dumping of Wastes and Other Matter. Available online: http://www.imo.org/en/OurWork/Environment/LCLP/Documents/LC1972.pdf (accessed on 15 August 2015).

6. 1996 Protocol to the Convention on the Prevention of Marine Pollution by Dumping of Wastes and Other Matter. 1972. Available online: http://www.imo.org/en/OurWork/Environment/LCLP/Documents/ PROTOCOLAmended2006.pdf (accessed on 15 August 2015).

7. Wong, S.I.; Sunarso, J.; Wong, B.T.; Lin, H.; Yu, A.; Jia, B. Towards enhanced energy density of graphene-based supercapacitors: Current status, approaches, and future directions. J. Power Sources 2018, 396, 182-206. [CrossRef]

8. Liu, Z.; Zhang, H.; Yang, Q.; Chen, Y. Graphene / V2O5 hybrid electrode for an asymmetric supercapacitor with high energy density in an organic electrolyte. Electrochim. Acta 2018, 287, 149-157. [CrossRef]

9. Tiwari, A.P.; Chae, S.-H.; Ojha, G.P.; Dahal, B.; Mukhiya, T.; Lee, M.; Chhetri, K.; Kim, T.; Kim, H.-Y. Three-dimensional porous carbonaceous network with in-situ entrapped metallic cobalt for supercapacitor application. J. Colloid Interface Sci. 2019, 553, 622-630. [CrossRef] [PubMed]

10. Kumar, S.; Saeed, G.; Zhy, L.; Hui, K.N.; Kim, N.H.; Lee, J.H. 0D to 3D carbon-based networks combined with pseudocapacitive electrode material for high energy density supercapacitor: A review. Chem. Eng. J. 2020, 403, 126352. [CrossRef]

11. Lin, C.-C.; Huang, H.-C. Radio frequency oxygen-plasma treatment of carbon nanotube electrodes for electrochemical capacitors. J. Power Sources 2009, 188, 332-337. [CrossRef]

12. Sahoo, G.; Polaki, S.R.; Ghosh, S.; Krishna, N.G.; Kamurddin, M.; Otrikov, K.K. Plasma-tuneable oxygen functionalization of vertical graphenes enhance electrochemical capacitor performance. Energy Storage Mater. 2018, 14, 297-305. [CrossRef]

13. Norikazu, K.; Yamada, H.; Yajima, T.; Sugiyama, K. Surface properties of activated carbon treated by cold plasma heating. Thin Solid Films 2007, 515, 4192-4196. [CrossRef]

14. Ishikawa, M.; Sakamoto, A.; Monta, M.; Matsuda, Y.; Ishida, K. Effect of treatment of activated carbon fiber cloth electrodes with cold plasma upon performance of electric double-layer capacitors. J. Power Sources 1996, 60, 233-238. [CrossRef]

15. Lota, G.; Tyczkowski, J.; Kapica, R.; Lota, K.; Frackowiak, E. Carbon materials modified by plasma treatment as electrodes for supercapacitors. J. Power Sources 2010, 195, 7535-7539. [CrossRef] 
16. Hsieh, C.-T.; Teng, H. Influence of oxygen treatment on electric double-layer capacitance of activated carbon fabrics. Carbon 2002, 40, 667-674. [CrossRef]

17. Kim, Y.-T.; Mitani, T. Competitive effect of carbon nanotubes oxidation on aqueous EDLC performance: Balancing hydrophilicity and conductivity. J. Power Sources 2006, 158, 1517-1522. [CrossRef]

18. Chen, C.; Ogino, A.; Wang, X.; Nagatsu, M. Oxygen functionalization of multiwall carbon nanotubes by Ar/H2O plasma treatment. Diam. Relat. Mater. 2011, 20, 153-156. [CrossRef]

(C) 2020 by the authors. Licensee MDPI, Basel, Switzerland. This article is an open access article distributed under the terms and conditions of the Creative Commons Attribution (CC BY) license (http://creativecommons.org/licenses/by/4.0/). 